\title{
Risk-Taking in Professional Groups
}

\author{
Scott Henderson ${ }^{1}$, Gillian Hyde ${ }^{2}$, Simmy Grover ${ }^{1}$, Adrian Furnham ${ }^{3}$ \\ ${ }^{1}$ Department of Clinical, Educational, and Health Psychology, University College London, London, UK \\ ${ }^{2}$ PCL Tunbridge-Wells, Tunbridge Wells, England \\ ${ }^{3}$ Norwegian Business School (BI), Nydalveien, Olso, Norway \\ Email: a.furnham@ucl.ac.uk
}

How to cite this paper: Henderson, S., Hyde, G., Grover, S., \& Furnham, A. (2021). Risk-Taking in Professional Groups. Psychology, 12, 1127-1140.

https://doi.org/10.4236/psych.2021.127069

Received: June 29, 2021

Accepted: July 26, 2021

Published: July 29, 2021

Copyright $\odot 2021$ by author(s) and Scientific Research Publishing Inc. This work is licensed under the Creative Commons Attribution International License (CC BY 4.0).

http://creativecommons.org/licenses/by/4.0/

(c) (i) Open Access

\begin{abstract}
This study focused on the risk-taking styles of people in different professional groups, with a focus on finance, compared to other occupational groups. A new risk-oriented personality questionnaire (Risk Type Compass) focusing on emotional and cognitive aspects of risk tolerance was used to analyse organisational groups, including financial markets traders. In all, 3592 professionals from different groups (e.g. HR, Engineering, Finance) completed the questionnaire. There were clear and interpretable differences between the groups. In a second study we contrasted the risk profiles of student and qualified groups in trading and finance. The findings support previous evidence that, in work settings, risk management is more important than risk-taking. There is a relative scarcity of research into occupational risk-taking and suggestions for further study into risk management, and counter-productive risk-taking are provided. Limitations and implications were discussed.
\end{abstract}

\section{Keywords}

Risk-Style, Finance, Traders, Cognitive, Emotional

\section{Introduction}

In two related studies this paper looks at the risk-taking preferences and styles of different professional groups (Andersen et al., 2019; Holzmeister et al., 2020). People's appetite for risk partly determines the jobs they seek and their success in those jobs, hence it may be expected that different occupational groups have very different risk-taking profiles.

Boyer (2006) defined risk-taking as voluntary participation in any behaviour which carries some probability for negative consequences. Individuals may vary in their perception of losses and their likelihood, and furthermore in their attitude to a given loss occurring. 
Individuals vary in their attitudes to different types of losses, and as such will choose different levels of risk in different domains. There are a number of different measures related to risk-taking, and this paper examines a new test. By far the most widely researched aspect of this field is personality dimension called Sensation Seeking. Zuckerman's (1994) fifth version of his Sensation-Seeking Scale (SSS-V) describes the four sub-scales: Thrill and Adventure Seeking (TAS); Experience Seeking (ES); Disinhibition (Dis); Boredom Susceptibility (BS). The first three relate respectively to a desire to achieve excitement through "extreme" physical sports, unconventional lifestyles, and hedonistic interaction with others. The fourth sub-scale relates to a desire simply to avoid monotony. Research has linked SSS-V to behaviour in domains as diverse as health, crime, and finance. For example, Wong and Carducci (1991) related it to self-reports of financial risk-taking. Zuckerman (2007) provides a comprehensive review of the development and validation of the SSS scales, noting its application to many areas of research.

Sensation-seeking is often considered part of a broader trait, impulsivity. There is some evidence that other facets of impulsivity are also related to risk-taking. Whiteside and Lynam (2001) devised the UPPS scale where the acronym stands for the four sub-scales: Urgency; (lack of) Premeditation; (lack of) Perseverance; and Sensation-Seeking. In a later version, the UPPS-P distinguishes between Positive and Negative Urgency (Lynam et al., 2007). Using the UPPS-P Cyders and Smith (2008) demonstrate that a tendency to gamble is better explained by Positive Urgency, the tendency to act impulsively when in a good mood, than by SSS.

Rogers et al. (2013) demonstrated that financial risk-taking is related to the ES and BS sub-scales of SSS-V, but further that instrumental (purposeful) financial risk-taking is positively related to Premeditation and Perseverance, and negatively related to Dis and Negative Urgency. This, more than any other research reviewed, demonstrates the benefits of precisely defining the domain of risk-taking in order to capture the influence of different personality facets depending on attitudes to those domains

Previous measures of risk attitudes and perceptions, such as the Domain Specific Risk-Taking Scale (DOSPERT; Weber et al., 2002) differentiated investment from gambling but with a narrow range of items, and without acknowledging that different investment decisions would be taken with different degrees of consideration. Rogers et al., (2013) also used the Triarchic Psychopathy Measure (TriPM; Patrick et al., 2009) to demonstrate the impact of psychopathy on risk-taking. The sub-scales of Boldness and Meanness were demonstrated to have positive relationships with instrumental financial risk-taking.

Furnham and Saipe (1993) used a standard personality test and showed that having been convicted of dangerous driving was related to high Psychoticism (P), low Neuroticism ( $\mathrm{N}$; as measured by the Eysenck Personality Questionnaire, (EPQ); Eysenck \& Eysenck, 1991) as well as high SSS. 
Research on risk-taking with respect to the five-factor model (FFM; Costa \& McCrae, 1992) is relatively sparse with conflicting evidence on the relationship between risk-taking and individual dimensions. Vollrath and Torgersen (2002) examined self-reported health risk-taking against combinations of high and low dimension scores, rather than individual scores. Using Torgersen's (1995) Basic Character Inventory they demonstrated that multiple risky health behaviours were related to high Neuroticism, or a combination of low Conscientiousness and high extraversion. Abstention was related to high Conscientiousness with low Extraversion.

Sensation-seeking, impulsivity, and psychopathy are therefore the main traits associated with risk-taking behaviour. However, other traits have also been studied and found important and significant. Butler and Matthews (1987) demonstrated that high "trait anxiety" would lead to over-estimation of risk in events related to oneself. Magar et al. (2008) showed that low self-regulation, as reflected by low scores in the Emotion Regulation Questionnaire (Gross \& John, 2003) were associated with higher levels of smoking and anti-social behaviour related to alcohol.

\section{The Study}

In this study we used the Risk-Type Compass which is a questionnaire that comprises two orthogonal dimensions: Daring/Measured and Emotional/Calm (PCL, 2013). Whether participants score high, medium or low on each scale determines their categorisation as one of nine different risk-types. Those who are highly Measured, as well as highly Emotional, are the least inclined to take risk, least able to cope with uncertain outcomes, and are described as the Wary Risk Type. Those with high scores on both Daring and Calm are inclined to take risk, are capable of handling uncertainty, and described as the Adventurous Risk Type. Figure 1 illustrates the full range of types in relation to the two dimensions.

The RTC has face validity. Each of the four dimensions has their equivalents in the literature. The Measured dimension reflects an individual's level of Conscientiousness. The inverse relationship between risk-taking and the Conscientiousness was established by Nicholson et al. (2005), and Skeel et al. (2007), and suggests that high scores for Measured should also be associated with lower levels of risk-taking. The Daring dimension could be interpreted as a measure of sensation-seeking,and should therefore be expected to relate directly to risk-taking. The Emotional dimension appears most closely related to HEXACO Emotionality which de Vries et al. (2009) have inversely related to risk-taking.

It is less clear that the Calm dimension will be related to risk-taking. It most closely resembles the HEXACO Agreeableness dimension which de Vries et al. (2009) found unrelated to risk-taking. In the two-dimension RTC, as well as the FFM, being trusted and forgiving are instead related to neuroticism. It appears 


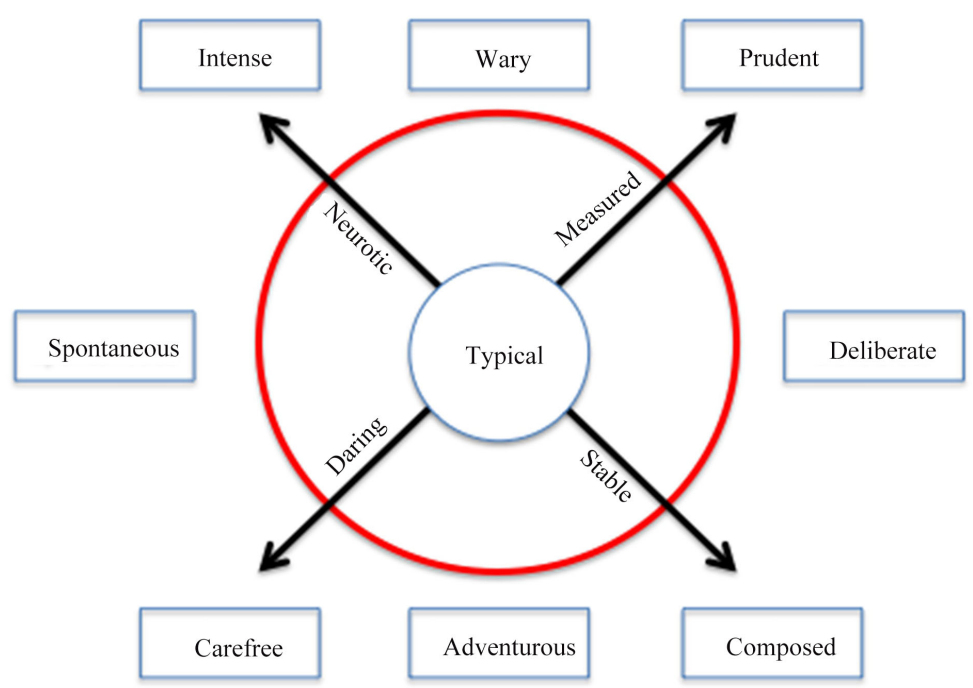

Figure 1. Risk-Type compass.

that being unforgiving and mistrustful are associated with lower risk-taking when they are caused by underlying emotional instability. However if such behaviour is determined by underlying skepticism the relationship to risk-taking is negligible or may be positive.

\subsection{Study 1}

Much risk-taking research has focused on particular populations, particularly adolescents, "dangerous sports" players and drivers. The hypothesis for this study is that there are significant differences in the mean scores of each dimension for different occupations, after controlling for gender and age. Secondly, that where there are skews in the prevalent RTC risk types in occupational groups, the mean differences of the dimensions and sub-scales will be significantly skewed accordingly. For example, those whose job titles include the words "risk" or "audit" appear more likely to be Deliberate and less likely to be Excitable, compared to the remaining population. The corresponding hypothesis is that the group will score significantly higher on Measured and/or significantly lower on Daring, and significantly higher on Calm and/or significantly lower on

\section{Emotional.}

The five largest professional groups were extracted from the main dataset: those with "risk" or "audit" in their title (Risk, $n=533$ ); those working in Engineering, Science or IT (Eng, $\mathrm{n}=216$ ); those working in front-line Public Sector jobs (PS, $\mathrm{n}=248$ ); those working in Human Resources or occupational psychology (HR, $\mathrm{n}=317$ ); and other White Collar workers (WC, $\mathrm{n}=1635$ ). Those that did not supply their age were excluded. Given the disproportionately large sample of WC, participant responses were randomly removed until the sample size was 607 Table 1.

Eight hypotheses were tested 
H1 WC will score significantly lower on Measured and/or higher on Daring, than all other groups

H2 WC will score significantly higher on Calm and/or lower on Emotional, than HR and PS

H3 PS will score significantly higher on Measured and/or lower on Daring, than WC and HR

H4 PS will score significantly lower on Calm and/or higher on Emotional, than all other groups

H5 Eng will score significantly higher on Measured and/or lower on Daring, than WC and HR

H6 Eng will score significantly higher on Calm and/or lower on Emotional, than HR and PS

H7 Risk will score significantly higher on Measured and/or lower on Daring, than WC and HR

H8 Risk will score significantly higher on Calm and/or lower on Emotional, than HR and PS

Table 1. Distribution of risk types within occupational groups.

\begin{tabular}{|c|c|c|c|c|c|c|c|}
\hline & & WC & HR & PS & Eng & Risk & Total \\
\hline \multirow[t]{2}{*}{ Prudent } & Count & 66 & 42 & 25 & 24 & 57 & 214 \\
\hline & $\%$ & $10.9 \%$ & $16.2 \%$ & $11.4 \%$ & $11.7 \%$ & $11.4 \%$ & $11.9 \%$ \\
\hline \multirow[t]{2}{*}{ Deliberate } & Count & 60 & 14 & 21 & 40 & 100 & 235 \\
\hline & $\%$ & $9.9 \%$ & $5.4 \%$ & $9.5 \%$ & $19.5 \%$ & $19.9 \%$ & $13.1 \%$ \\
\hline \multirow[t]{2}{*}{ Composed } & Count & 64 & 26 & 17 & 33 & 65 & 205 \\
\hline & $\%$ & $10.5 \%$ & $10.0 \%$ & $7.7 \%$ & $16.1 \%$ & $12.9 \%$ & $11.4 \%$ \\
\hline \multirow[t]{2}{*}{ Adventurous } & Count & 85 & 35 & 18 & 19 & 46 & 203 \\
\hline & $\%$ & $14.0 \%$ & $13.5 \%$ & $8.2 \%$ & $9.3 \%$ & $9.2 \%$ & $11.3 \%$ \\
\hline \multirow[t]{2}{*}{ Carefree } & Count & 67 & 35 & 26 & 18 & 52 & 198 \\
\hline & $\%$ & $11.0 \%$ & $13.5 \%$ & $11.8 \%$ & $8.8 \%$ & $10.4 \%$ & $11.0 \%$ \\
\hline \multirow[t]{2}{*}{ Spontaneous } & Count & 75 & 22 & 19 & 12 & 27 & 155 \\
\hline & $\%$ & $12.4 \%$ & $8.5 \%$ & $8.6 \%$ & $5.9 \%$ & $5.4 \%$ & $8.6 \%$ \\
\hline \multirow[t]{2}{*}{ Intense } & Count & 57 & 28 & 31 & 21 & 27 & 164 \\
\hline & $\%$ & $9.4 \%$ & $10.8 \%$ & $14.1 \%$ & $10.2 \%$ & $5.4 \%$ & $9.1 \%$ \\
\hline \multirow[t]{2}{*}{ Wary } & Count & 60 & 34 & 31 & 24 & 66 & 215 \\
\hline & $\%$ & $9.9 \%$ & $13.1 \%$ & $14.1 \%$ & $11.7 \%$ & $13.1 \%$ & $12.0 \%$ \\
\hline \multirow[t]{2}{*}{ Typical } & Count & 73 & 24 & 32 & 14 & 62 & 205 \\
\hline & $\%$ & $12.0 \%$ & $9.2 \%$ & $14.5 \%$ & $6.8 \%$ & $12.4 \%$ & $11.4 \%$ \\
\hline \multirow[t]{2}{*}{ Total } & Count & 607 & 260 & 220 & 205 & 502 & 1794 \\
\hline & $\%$ & $100.0 \%$ & $100.0 \%$ & $100.0 \%$ & $100.0 \%$ & $100.0 \%$ & $100.0 \%$ \\
\hline
\end{tabular}

\subsection{Method}

\section{Participants}

Participants $(\mathrm{n}=3592)$ comprised all those who had completed the RTC questionnaire over a five year period. $42 \%(\mathrm{n}=1522)$ were women, and $58 \%(\mathrm{n}=$ 2070) were men. Participants defined their occupation using free text. $15 \%$ used the term "risk" or "audit" in their job description. 9\% worked in Human Resources or as organisational psychologists. 7\% worked in front-line Public Sector jobs such as policing, firefighting, teaching and nursing. 6\% worked in Engineering, IT or scientific roles. $4 \%$ were students. $3 \%$ worked as Accountants, 
Actuaries or used the terms "finance" or "financial" in their job title. $45 \%$ were in a range of other white-collar jobs such as company

Table 2 and Table 3 show the resulting distribution of participants by gender and age, for each professional group.

\subsection{Risk-Type Compass}

The RTC questionnaire comprises 82 items of which ten are validity/lie-scale items and were removed from this analysis. Of the remaining 72, 40 form the Emotional/Calm dimension, and 32 form the Daring/Measured dimension. Items are based on themes that have been linked to risk-taking in prior research (PCL, 2013). The RTC is used primarily in occupational settings and groups from particular occupations are often skewed in the distribution of members' risk-types. Where perceived differences exist it is necessary to examine whether they are significant.

\section{Procedure}

Next, a MANOVA (followed by univariate ANOVAs) was computed with the 12 sub-scales as dependent variables between the five groups controlling for gender and age group. It was significant (Wilks Lambda .856; $\mathrm{F}(48,6836)=5.854, p$ $<.001$; Partial Eta Square .038). Next, the same MANOVA and ANOVAS were computed with the four dimensions as dependent variables. The MANOVA was significant (Wilks Lambda .919; $\mathrm{F}(16,5445)=9.528, p<.001$; Partial Eta Square .021). Table 4 shows the results of the ANOVAs on each sub-scale and dimension. The results of the Scheffe post-hoc analyses are partially indicated by the superscripts. To clarify further: the Neurotic/Calm means for HR, PS and WC were significantly higher than for Eng and Risk; the mean for HR was significantly higher than for WC; Eng, Risk and PS scored significantly higher on Measured than HR; Risk also scored higher on Measured than WC. H1, H3 and H5-H8 were all confirmed.

Table 2. Number of participants of each gender in each group.

\begin{tabular}{ccccccc}
\hline & WC & HR & PS & Eng & Risk & Total \\
\hline Male & 373 & 82 & 154 & 164 & 322 & 1095 \\
Female & 234 & 178 & 66 & 41 & 180 & 699 \\
\hline
\end{tabular}

Table 3. Number of participants of each age group in each professional group.

\begin{tabular}{ccccccc}
\hline & WC & HR & PS & Eng & Risk & Total \\
\hline 30 or under & 130 & 52 & 54 & 33 & 73 & 342 \\
$31-40$ & 153 & 79 & 71 & 51 & 141 & 495 \\
$41-50$ & 178 & 83 & 69 & 56 & 152 & 538 \\
Over 50 & 146 & 46 & 26 & 65 & 136 & 419 \\
Total & 607 & 260 & 220 & 205 & 502 & 1794 \\
\hline
\end{tabular}


Table 4. Mean Scores on the risk styles for five occupational groups.

\begin{tabular}{|c|c|c|c|c|c|c|c|c|c|c|c|}
\hline & \multicolumn{2}{|c|}{ White Collar $(\mathrm{n}=607)$} & \multicolumn{2}{|c|}{$\operatorname{HR}(n=260)$} & \multicolumn{2}{|c|}{ Public Sector $(n=220)$} & \multicolumn{2}{|c|}{ Engineering $(\mathrm{n}=205)$} & \multicolumn{2}{|c|}{ Risk/Audit $(\mathrm{n}=502)$} & \multirow[b]{2}{*}{ F Level } \\
\hline & $\mathrm{X}$ & SD & $\mathrm{X}$ & $\mathrm{SD}$ & $\mathrm{X}$ & SD & $\mathrm{X}$ & SD & $\mathrm{X}$ & SD & \\
\hline Confident & $9.06^{\mathrm{h}}$ & 2.03 & 8.66 & 2.03 & $8.50^{1}$ & 2.14 & 9.00 & 1.97 & $9.09^{\mathrm{h}}$ & 1.85 & $4.41^{* *}$ \\
\hline Adventurous & $18.60^{\mathrm{h}}$ & 2.93 & $18.52^{\mathrm{h}}$ & 3.12 & $17.35^{1}$ & 3.13 & 18.06 & 2.83 & $18.18^{\mathrm{h}}$ & 3.11 & $9.64^{* * *}$ \\
\hline Forgiving & 15.94 & 3.86 & 16.21 & 3.96 & 15.65 & 3.90 & 16.22 & 3.41 & 16.28 & 3.81 & 1.05 \\
\hline Sentimental & $20.39^{\text {lh }}$ & 5.43 & $21.54^{\mathrm{h}}$ & 4.78 & $20.34^{\mathrm{h}}$ & 4.93 & $18.59^{1}$ & 4.95 & $19.06^{1}$ & 4.79 & $7.41^{* * *}$ \\
\hline Emotion-Based Decisions & $11.46^{1}$ & 3.17 & $12.32^{\mathrm{h}}$ & 3.12 & $11.53^{\mathrm{h}}$ & 2.95 & $9.95^{1}$ & 3.06 & $10.57^{1}$ & 3.02 & $16.26^{* * *}$ \\
\hline Excitement Seeking & $21.03^{\mathrm{h}}$ & 4.98 & $19.21^{1}$ & 4.80 & $21.26^{\mathrm{h}}$ & 5.11 & $19.57^{1}$ & 5.17 & $20.00^{1}$ & 5.08 & $7.80^{\star * *}$ \\
\hline Trusting & $17.34^{\text {th }}$ & 3.09 & $18.02^{\mathrm{h}}$ & 2.82 & $16.34^{1}$ & 2.87 & $17.47^{\mathrm{h}}$ & 3.04 & $17.50^{\mathrm{h}}$ & 2.73 & $7.93^{* * *}$ \\
\hline Focused/Methodical & $40.63^{1}$ & 7.02 & $39.45^{1}$ & 6.99 & 41.00 & 6.53 & $41.70^{\mathrm{h}}$ & 7.21 & $42.32^{\mathrm{h}}$ & 7.07 & $10.74^{* * *}$ \\
\hline Apprehensive & $10.10^{1}$ & 3.12 & 10.72 & 3.12 & 10.50 & 3.08 & 10.14 & 2.85 & $10.66^{\mathrm{h}}$ & 2.90 & $3.06^{\star}$ \\
\hline Spontaneous & $18.69^{\mathrm{h}}$ & 3.12 & 18.25 & 3.01 & 18.11 & 3.12 & $17.74^{1}$ & 3.07 & $18.12^{1}$ & 3.10 & $5.85^{\star * *}$ \\
\hline Compliant & $14.03^{1}$ & 3.56 & $14.27^{1}$ & 3.54 & $15.36^{\mathrm{h}}$ & 3.07 & $15.08^{\mathrm{h}}$ & 3.42 & $15.62^{\mathrm{h}}$ & 3.20 & $22.02^{* * *}$ \\
\hline Patient & $7.15^{1}$ & 2.43 & 7.39 & 2.29 & $7.88^{\mathrm{h}}$ & 2.40 & $7.97^{\mathrm{h}}$ & 2.43 & $7.72^{\mathrm{h}}$ & 2.25 & $8.06^{* * *}$ \\
\hline Emotional & $41.95^{\text {lh }}$ & 8.85 & $44.57^{\mathrm{h}}$ & 7.67 & $42.36^{\mathrm{h}}$ & 8.25 & $38.67^{1}$ & 8.12 & $40.29^{1}$ & 7.64 & $8.29^{\star * *}$ \\
\hline Calm & 33.28 & 5.85 & $34.23^{\mathrm{h}}$ & 5.73 & $32.00^{1}$ & 5.69 & $33.70^{\mathrm{h}}$ & 5.20 & $33.78^{\mathrm{h}}$ & 5.47 & $12.65^{\star * *}$ \\
\hline Measured & $54.67^{1}$ & 9.01 & $53.72^{1}$ & 8.96 & $56.36^{\mathrm{h}}$ & 8.04 & $56.79^{\mathrm{h}}$ & 9.25 & $57.93^{\mathrm{h}}$ & 8.78 & $4.34^{* *}$ \\
\hline Daring & $81.23^{\mathrm{h}}$ & 10.22 & $78.25^{1}$ & 9.73 & $78.35^{1}$ & 10.01 & $77.39^{1}$ & 9.41 & $78.67^{1}$ & 9.61 & $18.04^{* * *}$ \\
\hline
\end{tabular}

$\mathrm{h}$ significantly higher than at least one other group, 1 significantly lower than at least one other group, ${ }^{* * *} p<.001,{ }^{* *} p<.01,{ }^{*} P<.05$.

$\mathrm{H} 2$ and $\mathrm{H} 4$ were unconfirmed because the higher Emotional and lower Calm scores of PS versus WC were not found to be significant. Possibly the differences in structure are responsible. More generally, it highlights the importance of analysing coherent groups. The disparate range of roles combined in the WC group makes the identification of meaningful differences less likely. It also highlights the limitations of determining the nature of the group using the single highest value, or other subjective appraisal.

Overall, it is clear that occupation is associated with significant personality differences beyond those determined by different gender and age distributions within each group. Further, in the groups studied there is evidence that differences in risk-type can be used to infer which traits are likely to differ significantly.

\subsection{Study 2: Financial Subgroups}

Having verified that significant differences in dimensions exist between different occupations it is possible to examine additional occupations. The purpose of study two was to examine whether financial market traders working for investment banks have significant differences in mean scores compared to non-trading financial workers and to students, and to determine whether such differences arise due to personality-occupation fit, or enculturation after joining the profes- 
sion.

Fenton O'Creevy et al. (2005) used the NEO personality inventory to compare traders, finance workers in and out of financial firms, and non-finance workers in and out of financial firms. They found that finance professionals scored more consistently with each other than did finance and non-finance workers in the same industry. The tentative conclusion drawn was that "selection and self-selection are at work more than socialization" (p134). For the trader group there were relatively few significant differences except that the group had lower Extraversion and Openness scores than other groups. No significant differences for sensation-seeking were identified.

Unlike the NEO, the risk-type compass (RTC) themes were derived to relate explicitly to risk-taking. The NEO Emotionality sub-scales are labeled Anxiety, Angry Hostility, Depression, Self-Consciousness, Impulsiveness and Vulnerability. In contrast, the RTC Emotional themes relate to a narrower range of emotional experience. There are many occupations where being anxious, hostile or depressed could be disruptive, but there are fewer occupations where sentimentality and making emotion-based decisions may lead directly to negative outcomes. However, trading is one such occupation because decisions are often made independently and rapidly giving no opportunity for discussion or reflection and the stakes can be very high. As such it is hypothesized that traders will score lower on Emotional than non-trading financial workers (H9), and versus students (H10).

For the same reasons, it is important for traders to create a structured framework in which to operate. Reactions to unexpected events are more effective when contingency plans exist, rather than when instantaneous decisions are made, which may be emotionally skewed. As such it is hypothesized that traders will score higher on Measured than non-trading financial workers (H11), and versus students (H12).

In order to assess whether selection or socialisation is responsible for differences in mean scores, a fourth sample was collected. Students training explicitly to become traders have already self-selected for that profession. Following the conclusion of Fenton O'Creevy et al. (2005) it is therefore likely that student traders will exhibit the same mean differences versus the financial group as professional traders. Student traders will score lower on Emotional than the financial group (H13), and versus non-trading students (H14). Student traders will score higher on Measured than the financial group (H15), and versus non-trading students (H16). It is not expected that significant differences will arise between the traders and student traders.

\section{Method}

Relevant samples were extracted from the main RTC dataset. Those that used the terms "finance", "financial" or "accountant" in their job title formed the finance group (Fin, $\mathrm{n}=99$ ). This captured financial advisers as well as those working in firm finance functions. Those that described their job title as "stu- 
dent" formed the other group (Stud, $\mathrm{n}=138$ ). It was assumed that few if any of this group would be trading students given the relative rarity of such courses.

The student trader sample was collected by distributing the RTC questionnaire to students at three institutions. Two of these were UK universities which run Masters programmes in finance, of which one component is principles of financial markets trading. The third is a London based private academy which teaches a similar syllabus to private individuals. All three courses are aimed at those looking to forge a career in the field but selection for participation was not based on an assessment of likely future success (St-Trad, $n=64$ ).

The trader sample was collected from volunteers at a variety of large investment banks (Trad, $n=44$ ). The majority of respondents were currency derivatives traders based in London $(\mathrm{n}=37)$. Mean length of experience was 9.6 years $(\min =1, \max =25$, s.d. $=5.95)$. All but one of the respondents were male. Demographics for all groups are shown in Table 5 and Table 6.

\section{Results}

As in Study 2, a MANOVA (followed by univariate ANOVAs) was computed with the 12 sub-scales as dependent variables between the four groups controlling for gender and age group. It was significant (Wilks Lambda .701; F(36, 964) $=3.42, p<.001$; Partial Eta Square .112). Next, the same MANOVA and ANOVAS were computed with the four dimensions as dependent variables. The MANOVA was significant (Wilks Lambda .815; $\mathrm{F}(12,884)=5.919, p<.001$; Partial Eta Square .066). Table 7 shows the results of the ANOVAs on each sub-scale and dimension. The results of the Scheffe post-hoc analyses are partially indicated by the superscripts.

With respect to Emotional, Stud scored higher than all other groups. The only significant difference between the two trading groups and the finance group was that Trad scored lower on Emotion-Based Decisions. H10 and H12 are accepted. H9 is tentatively accepted (on the basis of the sub-scale but not the dimension showing a significant difference). H11 is rejected.

Table 5. Number of participants of each gender in each group.

\begin{tabular}{cccccc}
\hline & Fin & Stud & St-Trad & Trad & Total \\
\hline Male & 75 & 55 & 55 & 43 & 228 \\
Female & 24 & 83 & 9 & 1 & 117 \\
\hline
\end{tabular}

Table 6. Number of participants of each age category in each group.

\begin{tabular}{cccccc}
\hline & Fin & Stud & St-Trad & Trad & Total \\
\hline 30 or under & 14 & 132 & 63 & 18 & 227 \\
$31-40$ & 21 & 5 & 1 & 19 & 46 \\
$41-50$ & 41 & 1 & 0 & 7 & 49 \\
Over 50 & 23 & 0 & 0 & 0 & 23 \\
Total & 99 & 138 & 64 & 44 & 345 \\
\hline
\end{tabular}


Table 7. Means of the four groups showing ANOVA results for each sub-scale and dimension.

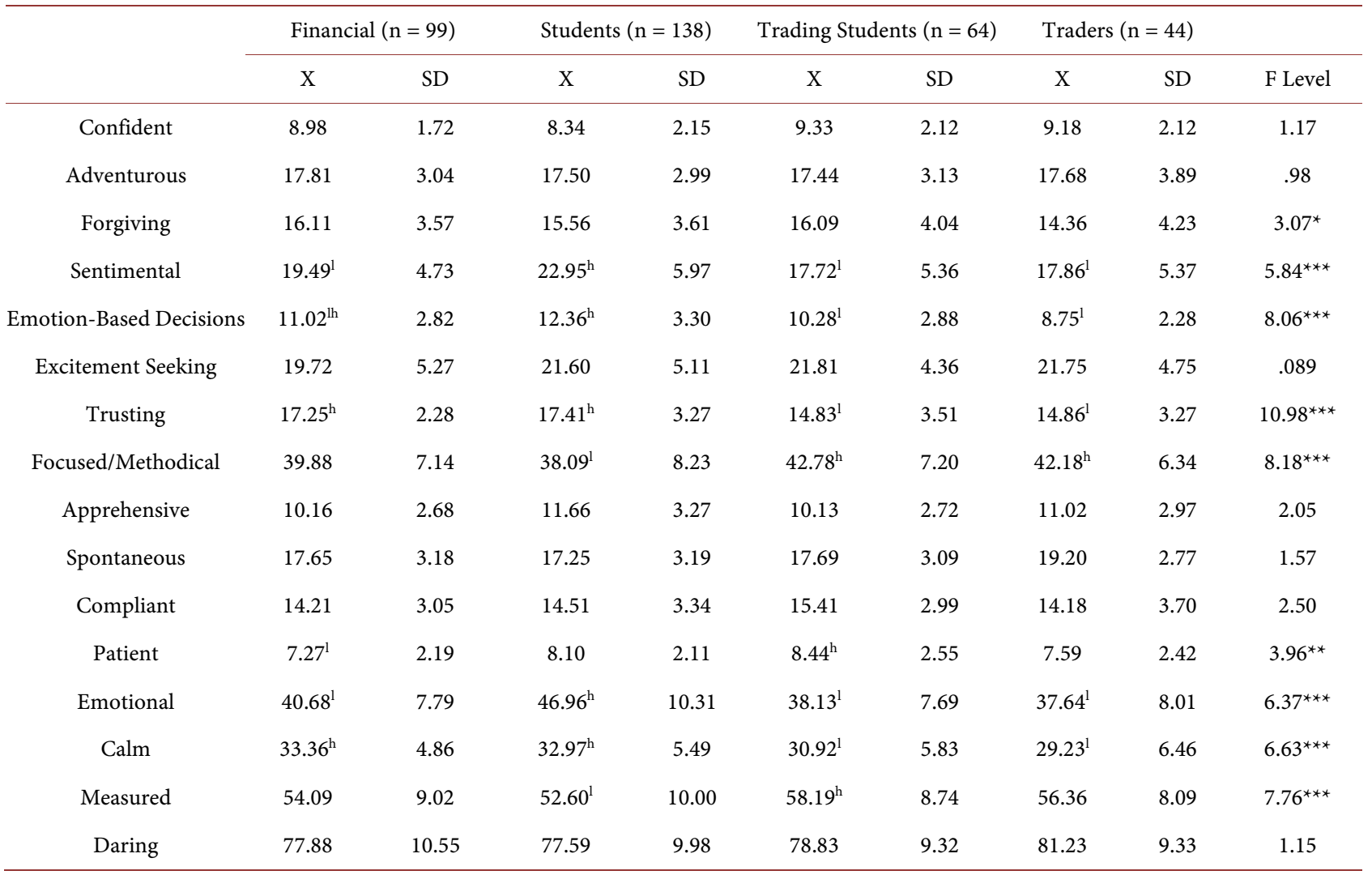

$\mathrm{h}$ significantly higher than at least one other group, 1 significantly lower than at least one other group, ${ }^{\star * *} p<.001,{ }^{* *} p<.01,{ }^{*} P<.05$.

A similar pattern emerged with respect to Measured. Trad scored higher than Stud on the Focused/Methodical sub-scale. St-Trad scored higher than Stud on the same sub-scale and Measured overall. However, there are no significant differences with Fin. H16 is accepted. H14 is tentatively accepted (on the basis of a significant sub-scale). H13 and H15 are rejected.

It is however worth noting that all the mean differences hypothesized did emerge at the dimension (and most sub-scale) levels, but that other than those highlighted the differences were not statistically significant. Given the relatively low sample size-particularly of the trader group-it is reasonable to suggest that were a larger sample available more significant results would emerge. Conversely, that no significant differences emerged between the traders and student traders indicates that self-selection is at work, but with a larger sample that may no longer hold true.

Of the significant differences related to the other dimensions the most striking is that Trad and St-Trad scored lower than both Stud and Fin on Trusting.

\section{Discussion}

Both studies in this paper suggest that occupation is associated with significant differences in "risk personality" beyond those determined by different demographic distributions within occupational groups. The first study showed that 
individuals who work in occupations that directly deal with risk are more Measured with their risk-taking style than Daring compared to individuals in white collar and human resources roles. Furthermore, they tend to be less Emotional and more Calm. This suggests that individuals in occupations that inherently involve risk may be better equipped at decision making in conditions that involve risk. This is unsurprising, as risk appetite, can be a major factor in both job selection and success.

In order to study this relationship, the second study looked to examine a specific group of individuals that deal with monetary risk taking on a regular basis.

\section{Trader Performance, and Risk-Taking}

Traders did not score significantly higher than other finance professionals on Measured, but it is clear that such a trait is important for financial services generally, and not least for trading. The non-student groups also scored lower on Emotional, but that traders did not score systematically lower than the finance and student trader groups indicates that being "ultra-calm" may not necessarily be an advantage. It may be that fearfulness is useful in small measures if it provokes action. However, this will only be beneficial if the stimulus for action is the trader's perception of the market and his/her exposure to it. Anxiety about status and job security is much more likely to be counterproductive, especially if it is misinterpreted as anxiety towards a trading decision.

That the trader group means for Emotion-Based Decisions was significantly lower than all other groups indicates that striving for rationality is essential, and is particularly important when closing positions, especially losing positions, holding on to loss making positions for sentimental reasons can quickly result in significant losses. This may be a trait that is selected or socialized, rather than self-selected. However, future research will need to investigate this by longitudinal research.

The two trading groups were significantly less trusting than the others. This indicates that mistrustful individuals are possibly attracted to trading, or that traders are conditioned not to trust those around them. This may be because technological developments have made financial markets one of the few environments in which it is unnecessary to trust your counterparty. The culture of banking, which tends to be highly competitive and instills a "dog-eat-dog" mentality, may reinforce the necessity to be mistrustful. Also, it may partly be because such individuals do not expect to be trusted by others that recent banking scandals have occurred (BBC, 2013; Guiso et al., 2008). This warrants further investigation because stricter regulation and constant surveillance (recording of all calls made on the trading floor) in the wake of the financial crisis may reinforce this culture yet further, and may therefore prove counterproductive (Giannetti \& Wang, 2016; Gurun et al., 2018).

Risk-taking and trading success are distinct concepts. Highly organised, rational, mistrustful, and selectively fearful individuals may not be proactive risk-takers, but they may be successful risk-managers. Fenton O'Creevy et al. (2005) argued 
that traders become risk-takers as a consequence of their environment rather than their personality. However, traders do have some control over the amount of risk they take, and if this is not due to sensation-seeking then alternative motives should be explored. Most notably these should include personal financial rewards as traders' compensation is often a percentage of the money that they make. The emergence of the concept of selective fearfulness indicates that emotional self-awareness and regulation are important for trading. This is consistent with the findings of Fenton O'Creevy et al. (2011).

Another trait that appears likely to relate to trading risk-taking and trading success is locus of control (Spector, 1982). The importance of feeling able to control outcomes in an unstable environment is very relevant to trading. In the research reviewed above, emotional self-regulation and internal locus of control were both found to be negatively related to risk-taking thus further indicating that traders are more likely to be risk-managers than risk-takers.

The evidence from the literature also suggests that whether traders are generating profits or losses will determine which personality traits have the greatest impact on behaviour. Sensation-seeking may dominate when making money, and Neuroticism may dominate when losing it. Coates (2012) provides evidence for the different neurobiological impacts of trading gains and losses. This would be usefully complemented by personality research.

There are various implications of this study. The first is the usefulness of using the RTC in assessment and selection. Clearly appetite for risk is relevant to many jobs and risk takes many forms. Second, it is important to know how people respond when their job requires that they take risks which may have important consequences. Third, risk appetite relates to both how and when people take risks, but also how they react to the consequences of their decisions. It would be interesting to know where the RTC types sit in Big Five Personality (FFM) factor space and also to other measures of motivation and ability

This study is not without its limitations. All data were self-report and it would be very desirable to have more details on the participants such as their work history and trading performance. Further psychometric work on the concurrent and predictivity of the RTC also needs to be carried out. Nevertheless, it shines a light on a relatively neglected area of research.

\section{Conflicts of Interest}

The authors declare no conflicts of interest regarding the publication of this paper.

\section{References}

Andersen, S., Hanspal, T., \& Nielsen, K. M. (2019). Once Bitten, Twice Shy: The Power of Personal Experiences in Risk Taking. Journal of Financial Economics, 132, 97-117.

https://doi.org/10.1016/j.jfineco.2018.10.018

BBC (2013). Libor Scandal: Can We Ever Trust Bankers Again?

http://www.bbc.co.uk/news/business-22382932 
Boyer, T. (2006). The Development of Risk-Taking: A Multi-Perspective Review. Developmental Review, 26, 291-345. https://doi.org/10.1016/j.dr.2006.05.002

Butler, G., \& Mathews, A. (1987). Anticipatory Anxiety and Risk Perception. Cognitive Therapy and Research, 11, 551-565. https://doi.org/10.1007/BF01183858

Coates, J. (2012). The Hour between Dog and Wolf: Risk Taking, Gut Feelings and the Biology of Boom and Bust. Penguin.com.

Costa, P., \& McCrae, R. (1992). Revised NEO Personality Inventory Manual. Psychological Assessment Resources.

Cyders, M., \& Smith, G. (2008). Clarifying the Role of Personality Dispositions in Risk for Increased Gambling Behavior. Personality and Individual Differences, 45, 503-508. https://doi.org/10.1016/j.paid.2008.06.002

De Vries, R. E., de Vries, A., \& Feij, J. A. (2009). Sensation Seeking, Risk-Taking, and the HEXACO Model of Personality. Personality and Individual Differences, 47, 536-540. https://doi.org/10.1016/j.paid.2009.05.029

Eysenck, H. J., \& Eysenck, S. B. G. (1991). Manual of the Eysenck Personality Scales (EPQ Adult). Hodder and Stoughton.

Fenton O’Creevy, M., Nicholson, N., Soane, E., \& Willman, P. (2005). Traders: Risks, Decisions, and Management in Financial Markets. Oxford University Press.

Fenton O’Creevy, M., Soane, E., Nicholson, N., \& Willman, P. (2011). Thinking, Feeling and Deciding: The Influence of Emotions on the Decision Making and Performance of Traders. Journal of Organizational Behavior, 32, 1044-1061. https://doi.org/10.1002/job.720

Furnham, A., \& Saipe, J. (1993). Personality Correlates of Convicted Drivers. Personality and Individual Differences, 14, 329-336. https://doi.org/10.1016/0191-8869(93)90131-L

Giannetti, M., \& Wang, T. Y. (2016). Corporate Scandals and Household Stock Market Participation. Journal of Finance, 71, 2591-2636. https://doi.org/10.1111/jofi.12399

Gross, J. J., \& John, O. P. (2003). Individual Differences in Two Emotion Regulation Processes: Implications for Affect, Relationships, and Well-Being. Journal of Personality and Social Psychology, 85, 348-362. https://doi.org/10.1037/0022-3514.85.2.348

Guiso, L., Sapienza, P., \& Zingales, L. (2008). Trusting the Stock Market. Journal of Finance, 63, 2557-2600. https://doi.org/10.1111/j.1540-6261.2008.01408.x

Gurun, U. G., Stoffman, N., \& Yonker, S. E. (2018). Trust Busting: The Effect of Fraud on Investor Behavior. Review of Financial Studies, 31, 1341-1376. https://doi.org/10.1093/rfs/hhx058

Holzmeister, F., Huber, J., Kirchler, M., Lindner, F., Weitzel, U., \& Zeisberger, S. (2020). What Drives Risk Perception? A Global Survey with Financial Professionals and Lay People. Management Science. https://doi.org/10.31219/osf.io/v6r9n

Lynam, D. R., Smith, G. T., Cyders, M. A., Fischer, S., \& Whiteside, S. P. (2007). The UPPS-P Questionnaire Measure of Five Dispositions to Rash Action. Unpublished Technical Report, Purdue University.

Magar, E. C. E., Phillips, L. H., \& Hosie, J. A. (2008). Self-Regulation and Risk-Taking. Personality and Individual Differences, 45, 153-159. https://doi.org/10.1016/j.paid.2008.03.014

Nicholson, N., Soane, E., Fenton-O'Creevy, M., \& Willman, P. (2005). Personality and Domain-Specific Risk Taking. Journal of Risk Research, 8, 157-176.

Patrick, C. J., Fowles, D. C., \& Krueger, R. F. (2009). Triarchic Conceptualization of Psychopathy: Developmental Origins of Disinhibition, Boldness, and Meanness. Development and Psychopathology, 21, 913-938. https://doi.org/10.1017/S0954579409000492 
PCL: Psychological Consultancy Limited (2013). Risk-Type Compass Manual. Psychological Consultancy Limited.

Rogers, J., Viding, E., \& Chamorro-Premuzic, T. (2013). Instrumental and Disinhibited Financial Risk Taking: Personality and Behavioural Correlates. Personality and Individual Differences, 55, 645-649. https://doi.org/10.1016/j.paid.2013.05.011

Skeel, R. L., Neudecker, J., Pilarski, C., \& Pytlak, K. (2007). The Utility of Personality Variables and Behaviorally-Based Measures in the Prediction of Risk-Taking Behavior. Personality and Individual Differences, 43, 203-214.

Spector, P. (1982). Behavior in Organizations as a Function of Employee's Locus of Control. Psychological Bulletin, 91, 482-497. https://doi.org/10.1037/0033-2909.91.3.482

Torgersen, S. (1995). Personlighet og personlighetsforstyrrelser. Universitetsforlaget.

Vollrath, M., \& Torgersen, S. (2002). Who Takes Health Risks? A Probe into Eight Personality Types. Personality and Individual Differences, 32, 1185-1197. https://doi.org/10.1016/S0191-8869(01)00080-0

Weber, E. U., Blais, A., \& Betz, N. (2002). A Domain-Specific Risk-Attitude Scale: Measuring Risk Perceptions and Risk Behaviors. Journal of Behavioral Decision Making, 15, 263-290. https://doi.org/10.1002/bdm.414

Whiteside, S. P., \& Lynam, D. (2001). The Five Factor Model and Impulsivity: Using a Structural Model of Personality to Understand Impulsivity. Personality and Individual Differences, 30, 669-689. https://doi.org/10.1016/S0191-8869(00)00064-7

Zuckerman, M. (1994). Behavioral Expressions and Biosocial Bases of Sensation-Seeking. Cambridge University Press.

Zuckerman, M. (2007). Sensation Seeking and Risky Behavior. American Psychological Association. https://doi.org/10.1037/11555-000 